\title{
INDEX OF SUBJECTS.
}

B. typhosus . . . . . . . . . . . 377,418

test, bacterial suspensions for . $\quad . \quad$. $\quad . \quad$. $\quad . \quad$. 55

see Enteric.

Bacteria, dissociation and variation . . . . . . . . . . . . 133

flora of diphtheria carriers and patients, etc. . . . . . . . . $\quad$. 228

"resting" or non-proliferating . . . . . . . . . . . . . . . . 139

see Agglutination.

Bacillus botulinus in Scottish soils . . . . . . . . . . . . . . . $\quad$. 79

diphtheriae, see Schick.

dysenteriae, organism allied to . . . . . . . . . . . . 355

dysenteriae (Sonne type III) . . . . . . . . . . . . 4

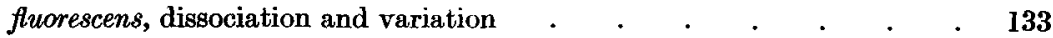

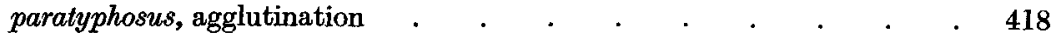

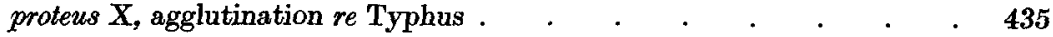

salmonicida . . . . . . . . . . . . . . . . . 71

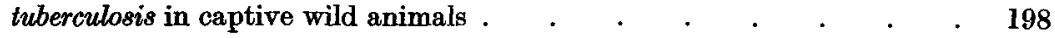

$\begin{array}{lllllllllllllll}\text { tuberculosis in Cow's faeces } & \text {. } & \text {. } & \text {. } & \text {. } & \text {. } & \text {. } & \text {. } & \text {. } & \text {. } & 89\end{array}$

typhosus, agglutination . . . . . . . . . . . . . . 377

see Enteric.

Bacterium aertrycke "mutton," discontinuous variation in virulence of . . . $\quad 295$

Micrococcus, green-producing, found in measles . . . . . . . . . . $\quad$. 363

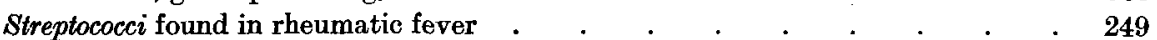

Baking-powders containing alum, dangers $\quad$. $\quad . \quad$. . . . . . . . . $\quad$. 92

Botulism, see Bacillus.

Bread, see Baking-powders.

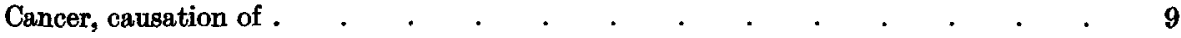

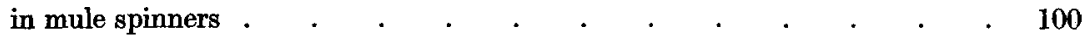

of respiratory tract, incidence in Leeds $\quad . \quad$. $\quad . \quad$. $\quad . \quad$. $\quad$. 340

see Skin.

Children, see Rheumatic, School.

Colds, see Epidemiology.

Complement-fixation (non-specific), see special index $\quad . \quad$. $\quad . \quad$. $\quad . \quad$. 172

see Foot-and-Mouth Disease.

Cuti-reactions, see Diphtheria, Measles.

Diphtheria carriers and patients, bacterial flora of . . . . . . . . . . 228

statistical study of . . . . . . . . . . . . . . . . 147

Diphtheria, see Schick.

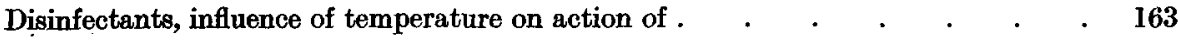

Dissociation (bacterial)

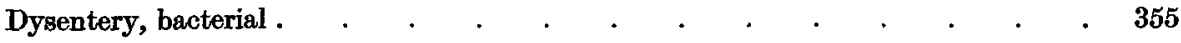

see Bacillus. 
Enteric fever in Palestine .

Fish, see Trout.

Foot-and-Mouth Disease, identifying types of virus . _ . . . . . . . . $\quad 325$

Furunculosis in trout

Immunity, see Agglutination, Complement, Foot-and-Mouth Disease, Infective, Schick.

Infective Disease, protection against

Leeds, see Cancer.

Lung Diseases, see Cancer. see Respiratory.

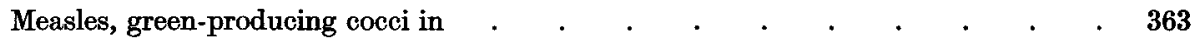

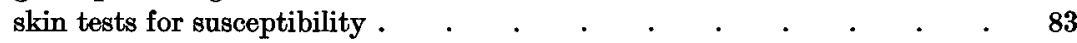

Mortality in infants, see Statistics, Cancer.

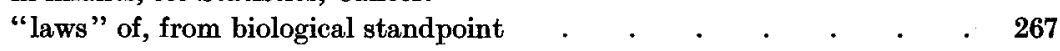

Mule Spinners' Cancer

Oils, effect on skin

Palestine, see Enteric.

Paratyphoid Fever, see B. paratyphosus.

Pasteurella infection in mice, studies on

Respiratory Diseases, epidemiology of

Rheumatic fever in Children, cause of

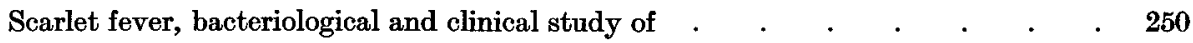

Schick toxin, stability of . statistical study of $. \quad . \quad . \quad . \quad . \quad . \quad . \quad . \quad . \quad . \quad 147$

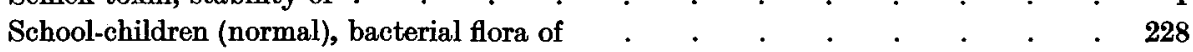

Sewage pollution of rivers, see Trout.

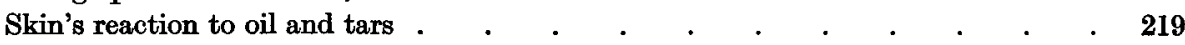

Skin-tests, see Cuti.

Statistical study of Scarlet Fever and Diphtheria . . . . . . . . . . $\quad$ - 147

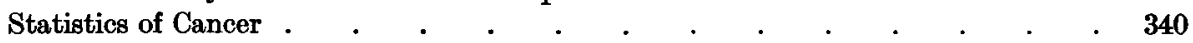

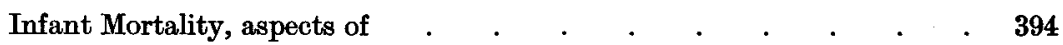
see Mortality, Enteric.

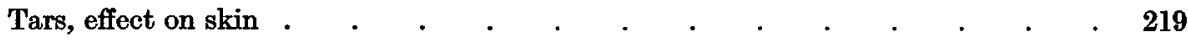

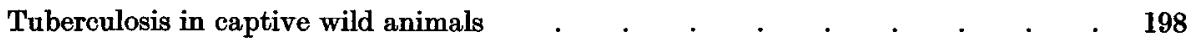

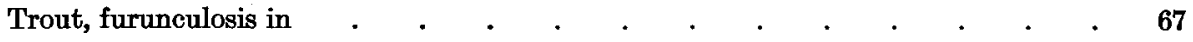

Tumours, see Cancer.

Typhoid fever, see Enteric.

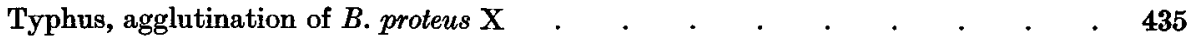

Variation, bacterial .

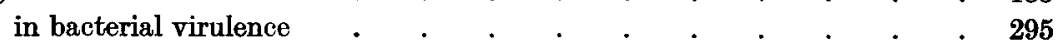

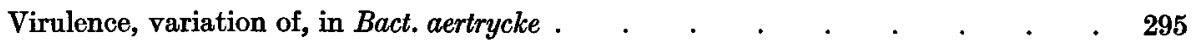

